\title{
Combined in situ infrared and mass spectrometric analysis of high-energy heavy ion induced degradation of polyvinyl polymers
}

\author{
Umme Habiba Hossain, ${ }^{* a b}$ Tim Seidlab $^{\text {ab }}$ and Wolfgang Ensinger ${ }^{a}$ \\ Degradation of polyvinyl polymers (polyvinyl formal, polyvinyl alcohol, and polyvinyl acetate) by high- \\ energy heavy ions was analysed with in situ mass spectrometry and infrared spectroscopy. Both at room \\ temperature and at cryogenic temperature, the polymers are severely damaged by scission of side \\ chains and the polymer backbone, releasing a large number of molecular fragments. Correlation of \\ structural analysis of the damaged polymer and mass analysis of its volatile fragments gives plausible \\ reaction mechanisms for the ion induced degradation. These are compared to thermal degradation. The \\ differences found between the two degradation processes are due to the non-equilibrium character of \\ the ion based process with its high electronic excitation and ionisation. The results are of practical \\ relevance for applications of the polymers in devices of particle accelerators and space vehicles.
}

Received 6th August 2013

Accepted 28th September 2013

DOI: $10.1039 / c 3 p y 01062 \mathrm{~g}$

www.rsc.org/polymers

It is well known that polymers exposed to ionizing radiation, particularly energetic ions, undergo several changes such as chemical structure degradation and, as a consequence, deterioration in material performance. ${ }^{6-13}$ Most intense material modifications take place when a polymeric material is exposed to heavy ion beams in the $\mathrm{MeV}-\mathrm{GeV}$ energy region in which the ions lose their energy localized with the energy transfer from the ions into the material being in the order of $\mathrm{keV} \mathrm{nm}^{-1}$. This is far beyond any chemical bond strength, high enough to break all covalent bonds within a few nanometres around the ion track. The interaction is characterized by bond breaking, crosslinking, formation of free radicals and various other reactions, which are induced by the complex secondary chemical processes along the trajectory of the ion. ${ }^{7}$ The fundamental events involved in ion irradiation of polymers are electronic excitation, ionization, and chain scission leading to outgassing of small volatile degradation products with the consequence of irreversible changes in material properties. Although the ion track formation in polymeric solids has been studied for years, ${ }^{6}$ there is still an incomplete understanding of the degradation mechanisms, particularly for certain polymers.

This study investigates the chemical modifications of polyvinyl formal induced by heavy ions by means of in situ Fourier Transform Infrared Spectroscopy (FTIR) and the outgassing of degradation products by means of online quadrupole mass spectroscopy (QMS).

Fig. 1 shows the chemical structure of polyvinyl formal. The complex structure of this random ter-polymer bears three subunits: acetal with a 1,3-dioxane ring (a), alcohol (b), and acetate (c), giving the full name (poly(vinyl acetale-co-vinyl alcohol-co-vinyl acetate). For a better understanding of ion induced degradation of this type of polymer we started a
${ }^{a}$ Technische Universität Darmstadt, Department of Materials Science, Materials Analysis, and Earth Sciences, Materials Analysis, Petersenstr. 23, 64287 Darmstadt, Germany. E-mail: u.h.hossain@gsi.de; Fax: +49-6151-166378; Tel: +49-6159-712651 ${ }^{b}$ GSI Helmholtz Centre of Heavy Ion Research, Planckstr. 1, D-64291 Darmstadt, Germany 


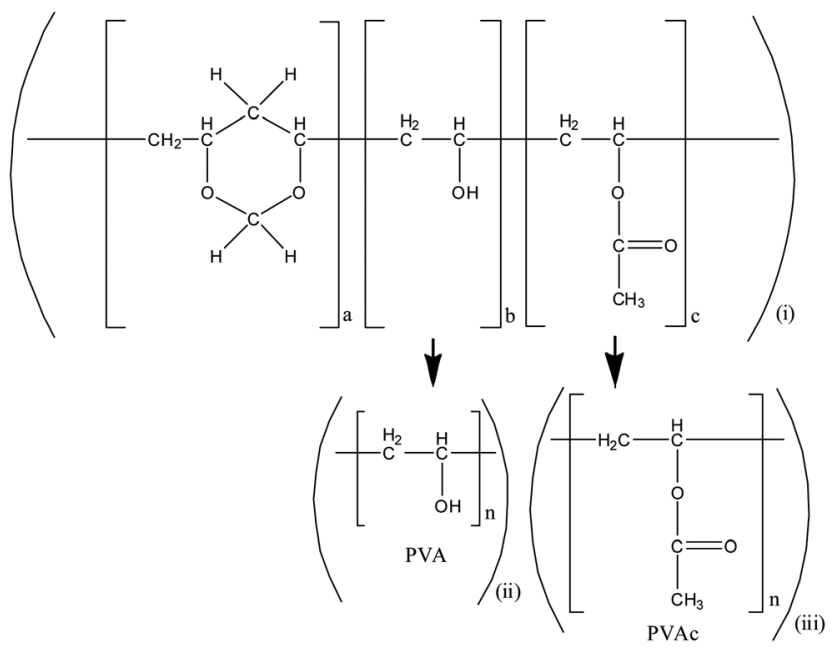

Fig. 1 Scheme representing the structure of (i) polyvinyl formal (PVF), (ii) polyvinyl alcohol (PVA) and (iii) polyvinyl acetate (PVAc).

systematic investigation, considering reference polymers such as polyvinyl alcohol (PVA) and polyvinyl acetate (PVAc), which are subunits of polyvinyl formal. The results are compared to those from the literature on thermal degradation. Exemplarily, low temperature in situ studies were performed to verify the obtained results for the cryogenic working temperature, both for superconducting magnets of accelerators and for components of space vehicles.

\section{Experimental}

\subsection{Sample preparation}

For transmission FTIR spectroscopy a polymer film in an expedient thickness, typically in the order of (1-40) $\mu \mathrm{m}$, is obligatory. Films of polyvinyl formal (Agar scientific, R1201), polyvinyl alcohol (Aldrich, Mw: 89 000-98 000) and polyvinyl acetate (Aldrich, Mw: 100 000) were prepared by the solution grown technique. All three polymers were weighed in solution concentrations of (4-8)\% and PVF and PVAc were dissolved in distilled dichloromethane $\left(\mathrm{CH}_{2} \mathrm{Cl}_{2}\right)$; for preparing PVA foil, water was used as solvent. The mixtures were stirred for $24 \mathrm{~h}$ at room temperature until clear solutions were obtained.

The viscous solution was dripped on a cleaned glass plate and the drop was streaked slowly with a squeegee to an area of about $10 \mathrm{~cm}^{2}$. After solvent evaporation in air for $24 \mathrm{~h}$, the polymer samples were carefully removed from the glass substrate. Homogeneous, transparent films were obtained without any gas bubbles having a thickness of (20-30) $\pm 2 \mu \mathrm{m}$ measured with a thickness gauge.

\subsection{Ion irradiation experiments}

The irradiation experiment was carried out at the M-Branch beam line of the Universal Linear Accelerator (UNILAC) at the GSI Helmholtz Centre of Heavy Ion Research Darmstadt, Germany. The experimental set up has been described elsewhere. ${ }^{\mathbf{1 3 , 1 4}}$ Sample irradiation is performed in the multipurpose diagnostic chamber at beam line M3 in a vacuum of typically
$10^{-5} \mathrm{~Pa}$. The chamber provides for in situ analysis of materials a FTIR spectroscope (coupled to the chamber via zinc-selenide windows) and a quadrupole mass spectrometer (QMS) for residual gas analysis. The target holder station is connected to a closed cycle refrigerator for low temperature experiments. The sample holder, where a maximum of 4 polymer foils of $1 \mathrm{~cm}^{2}$ area are mountable, is attached to the cooling finger in the centre of the chamber. The polymers were irradiated with $\mathrm{Au}$ ions of a kinetic energy of $4.5 \mathrm{MeV} \mathrm{u}^{-1}$, corresponding to around $900 \mathrm{MeV}$, using a pulsed ion beam of $5 \mathrm{~Hz}$ pulse repetition rate and $3 \mathrm{~ms}$ pulse length. The investigated parameter, relevant for radiation damage, is the ion fluence, given as the number of ions per unit area $\left(\mathrm{cm}^{-2}\right)$.

\subsection{Infrared spectroscopy}

FTIR spectral measurements were performed using a NICOLET 6700 spectrometer. For each spectrum, the average of 4 successive scans was recorded in the range of (4000-400) $\mathrm{cm}^{-1}$ with a resolution of $2 \mathrm{~cm}^{-1}$. The measurements were performed at an angle of $45^{\circ}$ with respect to the ion beam and sample surface. Software OMNIC 7.0 was used for data processing.

\subsection{Mass spectroscopy}

Outgassing degradation products were identified via quadrupole mass spectrometry. Mass-versus-yield analysis of gases was carried out with an E-Vision Plus, EVP-220-000 quadrupole residual gas analyser, which provides a detection range between $6.7 \times 10^{-12}$ and $6.5 \times 10^{-2}$ Pa for mass-to-charge $(\mathrm{m} / \mathrm{z})$ values from 1 to 200. The measurement was performed in analogue mode with a resolution of 0.03 . The acquisition time of each mass spectrum was approximately $35 \mathrm{~s}$ and the spectra were acquired continuously throughout the irradiation experiment.

\section{Results}

\subsection{Fourier-transform infrared spectroscopy}

As mentioned above, the ionizing radiation affects the molecular structure of the polymer. IR spectroscopy is an efficient tool for analyzing structural changes in situ. In the following section, IR spectroscopy results on PVF and its polymeric subunits PVA and PVAc are discussed in detail.

3.1.1 Polyvinyl formal (PVF). Fig. 2 shows the infrared absorption spectra of $12 \mu \mathrm{m}$ thick polyvinyl formal foil irradiated with $900 \mathrm{MeV} \mathrm{Au}$ ions at room temperature (RT). A very broad characteristic absorption peak centred at about 3490 $\mathrm{cm}^{-1}$ originates from the stretching vibration of the $-\mathrm{OH}$ groups. This broad band results from a combination of the $-\mathrm{OH}$ stretching vibration of the vinyl alcohol unit (at 3650-2800 $\mathrm{cm}^{-1}$ ) and of the carboxylic acid (impurity from the hydrolysis of the ester) around $3000 \mathrm{~cm}^{-1}$, as well as the first harmonic (at $3470 \mathrm{~cm}^{-1}$ ) of the $-\mathrm{O}-\mathrm{C}=\mathrm{O}$ ester carbonyl vibration of the acetate unit at $1735 \mathrm{~cm}^{-1}$. The five intense absorption bands in the (3040-2700) $\mathrm{cm}^{-1}$ region are identified as symmetric and asymmetric modes of the aliphatic $-\mathrm{CH},-\mathrm{CH}_{2}$ and $-\mathrm{CH}_{3}$-groups of the polymer backbone of acetale, alcohol and acetate. Ion irradiation within the explored fluence regime leads to a 


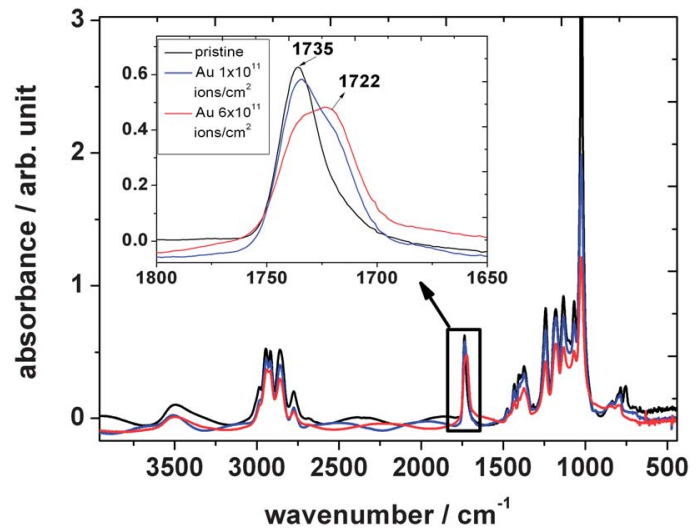

Fig. 2 FTIR spectra of polyvinyl formal before (black) and after (blue and red) irradiation with $4.5 \mathrm{MeV} \mathrm{u}^{-1} \mathrm{Au}$ ions performed at RT.

decrease in intensity of these bands mirroring the molecular degradation of the polymer. As mentioned before, the strong sharp band at $1735 \mathrm{~cm}^{-1}$ is attributed to the stretching vibration of the carbonyl group of the acetate side chain. While during irradiation this band decreases, like the other bands, a new feature appears close to it, a shoulder at around $1722 \mathrm{~cm}^{-1}$ (Fig. 2). Fig. 3 shows the evolution of the bands at $1735 \mathrm{~cm}^{-1}$ (A) and at $1722 \mathrm{~cm}^{-1}$ (B) after background subtraction with increasing ion fluence. While the band intensity of A decreases due to elimination of the acetate side chain, the production of $\mathrm{B}$, corresponding to a keto group, increases and finally saturates at about $3 \times 10^{11}$ ions $\mathrm{cm}^{-2}$. Deconvolution of the band at $1735 \mathrm{~cm}^{-1}$ of the dataset of the irradiated sample (blue curve in zoom of Fig. 2) using Lorentzian functions yields best results when fitting three bands namely at 1738,1722 , and $1682 \mathrm{~cm}^{-1}$ (Fig. 4 - blue, green and black curves). Since ester carbonyl groups typically absorb in the wavenumber region between 1750 and $1735 \mathrm{~cm}^{-1}$, we thus suggest that the two latter bands do not originate from the ester but rather have to be assigned to a ketone group $\left(1725-1705 \mathrm{~cm}^{-1}\right)$ and a $\mathrm{C}=\mathrm{C}$ double bond $(1682$ $\mathrm{cm}^{-1}$ ) formed by the elimination of hydrogen or water from the vinyl alcohol unit.

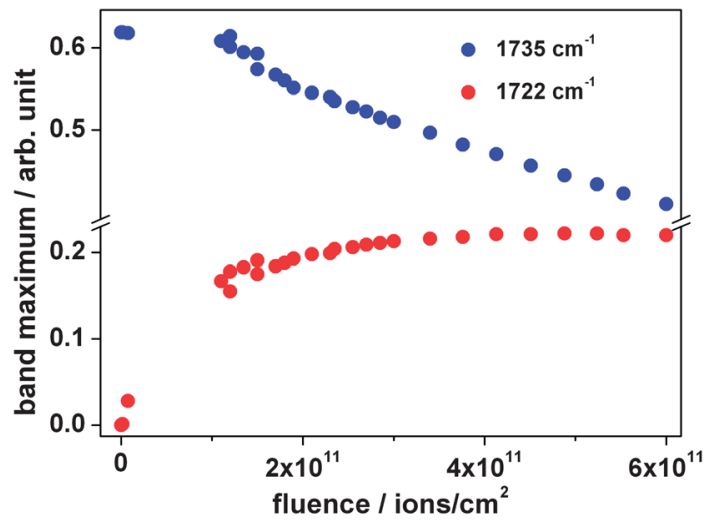

Fig. 3 Maximum intensity of absorption bands at 1735 and $1722 \mathrm{~cm}^{-1}$ as a function of the fluence during irradiation with $4.5 \mathrm{MeV} \mathrm{u}^{-1} \mathrm{Au}$ ions.

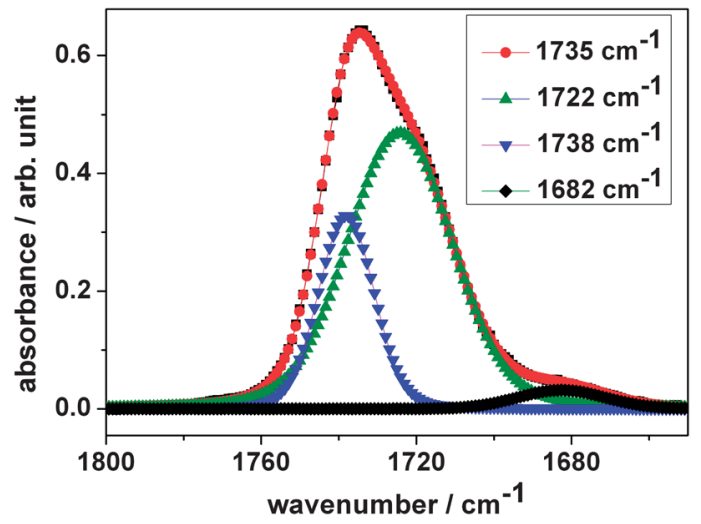

Fig. 4 Band deconvolution of the irradiated dataset using Lorentzian functions as a fit.

The fingerprint region between 1500 and $500 \mathrm{~cm}^{-1}$ contains a complex series of absorption bands. These may be ascribed to (1) stretching $\mathrm{C}-\mathrm{O}$ vibrations, (2) wagging, twisting and rocking vibrations of the chain $-\mathrm{CH}_{2}$ group, (3) out-of-plane bending vibrations of the polymer backbone and formal groups. According to the literature the bands at $1018 \mathrm{~cm}^{-1}$ correspond to the out-of-plane bending vibration of the $-\mathrm{CH}$ bands ${ }^{15}$ and have a very high absorbance compared to the other bands in this region. The vibrational band at $1372 \mathrm{~cm}^{-1}$ is assigned to the in-plane bending vibration of $-\mathrm{CH}$. The band at $1432 \mathrm{~cm}^{-1}$ is described in the literature as wagging $-\mathrm{CH}_{2}$ vibrations, and the band at $780 \mathrm{~cm}^{-1}$ originates from stretching and rocking $\mathrm{C}-\mathrm{O}$ vibrations. According to literature data, ${ }^{16-18}$ the band at 749 $\mathrm{cm}^{-1}$ is assigned to the $\mathrm{O}-\mathrm{C}=\mathrm{O}$ in-plane bending vibration. During irradiation all band intensities in the fingerprint region decrease with increasing ion fluence. However, the absorption band at $749 \mathrm{~cm}^{-1}$ exhibits a considerably stronger decrease compared to all other bands and disappears at a fluence of around $6 \times 11^{11}$ ions per $\mathrm{cm}^{2}$. This may be attributed to the breaking of ester bonds when the acetate side chain is eliminated.

Temperature dependent changes in the peak intensity of several representative absorption bands of polyvinyl formal are shown in Fig. 5. The spectrum of polyvinyl formal at around 40 $\mathrm{K}$ is similar to the corresponding spectrum of polyvinyl formal at $290 \mathrm{~K}$ and gives very similar results during irradiation, namely (a) an overall reduction in absorption intensity of the characteristic bands and (b) the appearance of a new absorption band at around $1722 \mathrm{~cm}^{-1}$.

In summary, it can be stated that ion irradiation of polyvinyl formal leads to a general degradation of the subunits acetal, alcohol and acetate, with scission of the $\mathrm{C}-\mathrm{C}$ backbone, the acetale ring, and elimination of the side chains of acetate and alcohol. Oxygen-bearing parts with hydroxyl and ester/acetate at the backbone are partially changed into keto groups. $\mathrm{C}-\mathrm{H}$ bonds are reduced in number, and the number of $\mathrm{C}=\mathrm{C}$ bonds is slightly increased.

3.1.2 Polyvinyl acetate (PVAc). Fig. 6 represents the FTIR spectra of a $20 \mu \mathrm{m}$ polyvinyl acetate foil irradiated with Au ions in comparison with the non-irradiated foil (room temperature). 


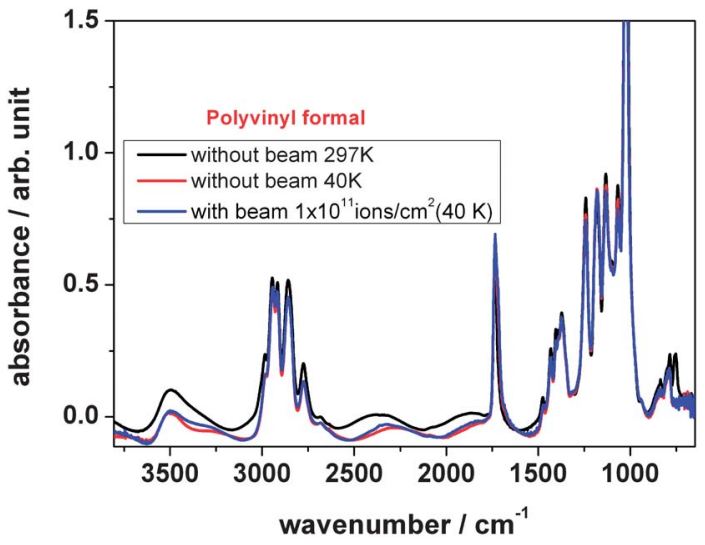

Fig. 5 FTIR spectra of polyvinyl formal during irradiation at $40 \mathrm{~K}$ and RT.

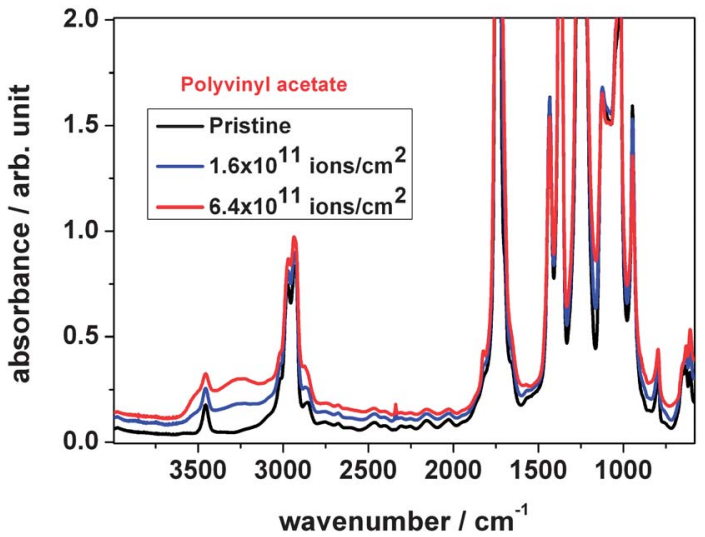

Fig. 6 FTIR spectra of polyvinyl acetate irradiated with different fluences.

According to the literature, ${ }^{19,20}$ the major absorption bands of polyvinyl acetate are as follows.

A broad band is found at $3456 \mathrm{~cm}^{-1}$ of polyvinyl acetate assigned as the first harmonic of the ester carbonyl vibration $(2 \times \mathrm{O}-\mathrm{C}=\mathrm{O})$ at $1736 \mathrm{~cm}^{-1}$. The typical four vibration bands of aliphatic groups (3001, 2970, 2925 and $2851 \mathrm{~cm}^{-1}$ ) assigned to symmetric and asymmetric vibration modes show weak absorbance. A band at $1736 \mathrm{~cm}^{-1}$ is identified as the carbonyl stretching vibration.

The region from 1700 to $500 \mathrm{~cm}^{-1}$ is composed of stretching $-\mathrm{C}-\mathrm{O}$ vibrations, rocking, wagging and twisting vibrations of $-\mathrm{CH}_{2}$ groups, out of plane bending vibrations of the $-\mathrm{CH}$ chain and one or more stretching vibrations of the polymer chain.

As shown in Fig. 6, the wavenumber and peak intensity of the IR absorption bands changed significantly upon ion irradiation. Once the foil was irradiated with a fluence beyond $1 \times 10^{11}$ ions per $\mathrm{cm}^{2}$, the background increased, while the intensities of characteristic absorption bands at 3001, 2970, 2925, 2851 and $1736 \mathrm{~cm}^{-1}$ as well as the bands at the fingerprint region from 1700 to $500 \mathrm{~cm}^{-1}$ decreased.

During irradiation the carbonyl stretching vibration band at $1736 \mathrm{~cm}^{-1}$ shows a tendency to decrease, while the shoulder at around $1714 \mathrm{~cm}^{-1}$ increases, see Fig. 7, left. This could be interpreted as an additional hydroxyl band. The figure also shows that

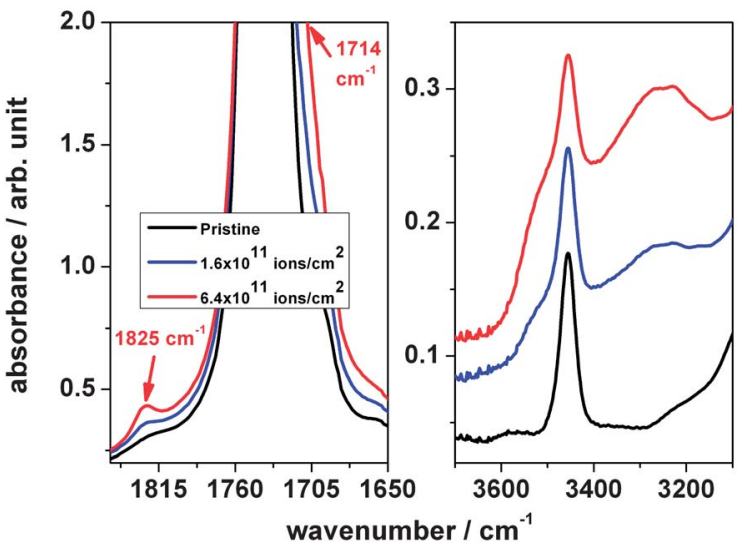

Fig. 7 Expanded FTIR spectra of polyvinyl acetate irradiated with different fluences; left: the region of $1850-1600 \mathrm{~cm}^{-1}$ and right: the region of $3700-3100 \mathrm{~cm}^{-1}$.

a new band appears at around $1825 \mathrm{~cm}^{-1}$. According to the literature, ${ }^{21}$ the region $1850-1745 \mathrm{~cm}^{-1}$ can be assigned to (i) acid anhydride, (ii) peroxy acid or (iii) lactone. Peroxy acids, commonly synthesized via reactions of peroxides with carboxylic acid, are unstable molecules and are unlikely to be formed under the given conditions. Acetic anhydride and lactones, the cyclic esters of hydrocarbon acids, such as $\gamma$-butyrolactone or $\delta$-valerolactone, can be produced via thermal degradation and therefore could be an explanation for the band. Therefore, the acetate with a ringforming reaction or the formation of acetic anhydride might be the source of the new band.

During irradiation the overtone peak of the acetate band at $3456 \mathrm{~cm}^{-1}$ was observed (Fig. 7, right) to increase the intensity because of a broad absorption band beneath, assigned to $-\mathrm{OH}$. After subtraction of this band the peak area is found to decrease with ion fluence, which is correlated with the increase of the stretching mode of the $-\mathrm{OH}$ band. This result supports $-\mathrm{OH}$ formation as a consequence of the scission of the ester group of the acetate side chain.

The non-oxidative thermal decomposition of PVAc has been studied by several groups. Throughout the literature, one finds that PVAc in the first step degrades by elimination of acetic acid from the side chain, leading to carbon double bonds. Grassie had claimed that a polyene residue is developed, ${ }^{22}$ Troitskii et al. described the kinetics, ${ }^{23}$ and Ballistieri et al. found a twostep process, including elimination of acetic acid as the first step, followed by the formation of aromatic hydrocarbons. ${ }^{24}$ Holland and Hay found new bands at 1600 and $3070 \mathrm{~cm}^{-1}$ in the IR spectrum which were assigned to $\mathrm{C}=\mathrm{C}$ bonds and $\mathrm{C}-\mathrm{H}$ bonds which are adjacent to $\mathrm{C}=\mathrm{C}$ bonds. ${ }^{25}$ Additionally, they also found indications of the presence of ketones while acetate bands of the side chains at $1240 \mathrm{~cm}^{-1}$ decreased in their intensity. They describe a process with elimination of acetic acid and acetic anhydride by hydrolysis, leaving back a hydroxyl group which turns into a keto group by double bond migration. A similar mechanism is the formation of ketene, also followed by double bond migration. Additionally they claimed four- and six-membered elimination reactions of acetate side groups, leading to polyenes. They conclude that formation of acetic acid 
increases as the degradation process proceeds, due the increasing formation of $\mathrm{C}=\mathrm{C}$ bonds. Costa et al. investigated the degradation of PVAc in a nitrogen atmosphere. ${ }^{26}$ The degradation started at $300{ }^{\circ} \mathrm{C}$. The ester bands $(-\mathrm{C}=\mathrm{O}$ stretching at 1749, $-\mathrm{CH}_{3}$ bending at 1370 (1365) $\mathrm{cm}^{-1}$, and $\mathrm{C}-\mathrm{O}$ stretching at $1264 \mathrm{~cm}^{-1}$ ) were decreased. Double bonds $\mathrm{C}=\mathrm{C}$ were formed at $990-960 \mathrm{~cm}^{-1}$. Elimination of ketene led to $\mathrm{O}-\mathrm{H}$ stretching at $3460 \mathrm{~cm}^{-1}$.

Hence, both thermal and ion induced degradation show a reduction of the number of aliphatic $\mathrm{C}-\mathrm{H}$ groups, elimination of the acetate side groups, and an increase in hydroxyl groups due to the ester scission. Additionally, some formation of keto groups from reaction of the hydroxyl groups was found.

3.1.3 Polyvinyl alcohol (PVA). Fig. 8 shows the FTIR spectra of irradiated polyvinyl alcohol in comparison with the nonirradiated foil. The characteristic vibration bands of PVA can be assigned to the vibration of $\mathrm{C}-\mathrm{OH}, \mathrm{C}-\mathrm{H}, \mathrm{C}=\mathrm{O}$ and $\mathrm{C}-\mathrm{O}$ bonds. Above $3000 \mathrm{~cm}^{-1}$, the absorption of PVA gives indication of a broad and very strong absorption band, which derives from the stretching vibration of the hydroxyl group (at 3650-2800 $\mathrm{cm}^{-1}$ ). In the wavenumber range $3000-2800 \mathrm{~cm}^{-1}$ PVA exhibits two absorbance bands at 2943 and $2912 \mathrm{~cm}^{-1}$. They correspond to the symmetric and asymmetric stretching vibrations of $-\mathrm{CH}_{2}$ groups. ${ }^{21}$ Three characteristic vibration bands of carbonyl function are found at 1707, 1657 and $1564 \mathrm{~cm}^{-1}$, where the band at $1564 \mathrm{~cm}^{-1}$ can be identified as stretching vibrations of $\mathrm{C}=\mathrm{O}$ groups attached to hydroxyl groups via hydrogen bonds. The bending vibrations of the $\mathrm{C}-\mathrm{H}$ bands are located at 1427 and $1334 \mathrm{~cm}^{-1}$. The two bands found at 1371 and $1085 \mathrm{~cm}^{-1}$ are assigned to the $\mathrm{C}-\mathrm{O}-\mathrm{H}$ bending and $\mathrm{C}-\mathrm{O}$ stretching coupled with $\mathrm{O}-\mathrm{H}$ bending vibrations. An absorption band at $1135 \mathrm{~cm}^{-1}$ originates from the $\mathrm{C}-\mathrm{C}$ and $\mathrm{C}-\mathrm{O}-\mathrm{C}$ stretching vibrations of the PVA polymer. At the spectral region of low wavenumbers, the absorption bands at 916 and $848 \mathrm{~cm}^{-1}$ can be assigned to the presence of $-\mathrm{CH}_{2}$ bonds.

As shown in Fig. 8, the peak intensities of the IR spectra changed significantly with the increase of the number of ions hitting the material. Before irradiation the hydroxyl band (3600$3000 \mathrm{~cm}^{-1}$ ) shows a noisy peak, which is due to the high absorbance saturation effect. During irradiation this band

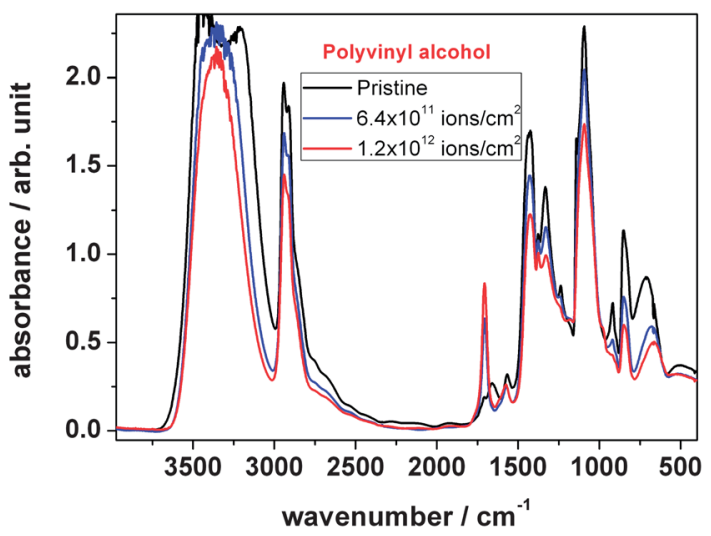

Fig. 8 FTIR spectra of polyvinyl alcohol, comparing the unirradiated material with the one treated with two different ion fluences. becomes smaller and sharper, which indicates the decrease of the number of hydroxyl groups with an increase in fluence due to their elimination. The peak intensity at $1702 \mathrm{~cm}^{-1}$, corresponding to carbonyl formation, increases and the peak at $916 \mathrm{~cm}^{-1}$ of $-\mathrm{CH}_{2}$ bonds disappears. A strong reduction of the number of $-\mathrm{OH}$ groups while $-\mathrm{C}=\mathrm{O}$ increases indicates on one hand that the hydroxyl group is dehydrogenated forming an oxygen double bond; on the other hand the hydroxyl group can be eliminated by $\mathrm{H}_{2} \mathrm{O}$ formation in combination with backbone hydrogen abstraction leading to the loss of $-\mathrm{CH}_{2}$ by $\mathrm{C}=\mathrm{C}$ double bond formation.

This mechanism seems to be similar to the one found for thermal decomposition. Tsuchiya and Sumi carried out an early investigation on non-oxidative thermal decomposition of PVA. ${ }^{27}$ They state that the mechanism is based on elimination of the -OH group as water, leaving a conjugated polyene structure behind. Scission of $\mathrm{CC}$ bonds leads to formation of mainly terminal $\mathrm{C}=\mathrm{O}$ groups with adjacent $\mathrm{C}=\mathrm{C}$ groups. Thomas et al. described the thermal degradation of polyvinyl alcohol in a nonoxidizing gas atmosphere, namely nitrogen, with elimination of water from the - $\mathrm{OH}$ groups as the first step, followed by pyrolysation..$^{28}$ Their IR measurements show a slow decay of the $\mathrm{O}-\mathrm{H}$ stretching mode at $3370 \mathrm{~cm}^{-1}$, followed by a sharp drop at around $240{ }^{\circ} \mathrm{C}$ to very low levels. The $\mathrm{C}-\mathrm{H}$ stretching mode at $2940 \mathrm{~cm}^{-1}$ is less affected at lower temperature, however, does also drop at $240{ }^{\circ} \mathrm{C}$. In the same temperature regime, the $\mathrm{C}=\mathrm{O}$ and $\mathrm{C}=\mathrm{C}$ stretching modes at $1715 \mathrm{~cm}^{-1}$ and $1595 \mathrm{~cm}^{-1}$ appear. The melt temperature was in this regime. The authors conclude that chain scission and rearrangement yields the carbonyl group as a product. The $\mathrm{C}=\mathrm{C}$ modes increase, but not very much due to formation of aromatic species upon further degradation. Holland and Hay degraded PVA in argon gas at a temperature between 260 and $290{ }^{\circ} \mathrm{C} .{ }^{29}$ They observed a reduction of $-\mathrm{OH}$ bands at $3450 \mathrm{~cm}^{-1}$ and of $-\mathrm{C}-\mathrm{H}$ at 2930 $\mathrm{cm}^{-1}$. At $1705 \mathrm{~cm}^{-1}$, a band assigned to unsaturated $-\mathrm{C}=\mathrm{O}$ was formed. They explain their observation by elimination of water with formation of a $\mathrm{C}=\mathrm{C}$ double bond which migrates towards the next hydroxyl group leading to formation of a keto group due to keto-enol tautomerization. This process eliminates the $\mathrm{C}=\mathrm{C}$ bond, thus explaining the much higher loss rate of $-\mathrm{O}-\mathrm{H}$ groups in comparison to $-\mathrm{C}-\mathrm{H}$ groups.

The comparison shows that both due to heat and ion energy input into PVA the hydroxyl groups are either eliminated or dehydrogenate into a keto group. Additionally, the $\mathrm{CH}$ backbone loses hydrogen, forming $\mathrm{C}=\mathrm{C}$ bonds.

\subsection{Mass spectrometric analysis of volatile molecular fragments}

As mentioned before, the analysis of ion induced fragmentation into small volatile molecules was performed by means of mass spectrometry (residual gas analysis). In the following, the individual behaviour of the components of PVF is discussed.

3.2.1 Polyvinyl formal. Online analysis of the gases in a vacuum chamber by means of mass spectroscopy allowed us to obtain detailed information about the volatile degradation products produced during irradiation of polyvinyl formal. Fig. 9 
shows a typical mass spectrum of polyvinyl formal together with the ones of polyvinyl acetate and polyvinyl alcohol recorded at room temperature during irradiation with a flux of $2 \times 10^{7} \mathrm{Au}$ ions per $\mathrm{cm}^{2} \mathrm{~s}$ at around $900 \mathrm{MeV}$ kinetic ion energy. All molecular masses within the range of $0-100 \mathrm{~m} / \mathrm{z}$ were checked for changes in comparison to the situation without ion irradiation. The vacuum chamber with the polymer on the sample holder shows a typical background spectrum, arising from gas desorption from the chamber walls, leakage, outgassing of the polymer, and to a small extent from the vacuum pump system such as oil from the forepumps.

It is observed that outgassing of polyvinyl formal under ion bombardment leads to an intensity increase of volatile species like hydrogen $\left(\mathrm{H}_{2}, m / z=2\right)$, carbon $(\mathrm{C}, \mathrm{m} / z=12)$, oxygen $(\mathrm{O}, \mathrm{m} /$ $z=16)$, hydroxyl $(\mathrm{OH}, m / z=17)$, water $\left(\mathrm{H}_{2} \mathrm{O}, m / z=18\right)$, a carbon monoxide with some contribution of ethene $\left(\mathrm{CO} / \mathrm{C}_{2} \mathrm{H}_{4}, m / z=\right.$ 28 ), ethyne $\left(\mathrm{C}_{2} \mathrm{H}_{2} m / z=26\right)$, carbon dioxide and acetaldehyde $\left(\mathrm{CO}_{2} / \mathrm{C}_{2} \mathrm{H}_{4} \mathrm{O}, m / z=44\right)$, and some larger species such as $\mathrm{C}_{4} \mathrm{H}_{3-6} \mathrm{O}_{2}(m / z=83-86)$, and to species not corresponding to regular molecules, either ionic or radical, like $\mathrm{C}_{2} \mathrm{H}_{3} \mathrm{O}(\mathrm{m} / \mathrm{z}=43)$ and $\mathrm{C}_{3} \mathrm{H}_{5} \mathrm{O}(\mathrm{m} / \mathrm{z}=57)$. During irradiation of polyvinyl formal, a new volatile molecule appears at $m / z=36$. According to the mass number, the only reasonable molecule would be the doubly charged ion of $\mathrm{C}_{3} \mathrm{H}_{4} \mathrm{O}_{2}$. This interpretation, however, requires a peak of $\mathbf{M}^{+}$(singly charged $\mathrm{C}_{3} \mathrm{H}_{4} \mathrm{O}_{2}$ ) at $m / z=72$. Since there is no corresponding mass found in the spectrum, additional chemical elements have to be considered. One possible interpretation of this peak at $m / z=36$ may be derivatives of $\mathrm{HCl}$. During preparation of polyvinyl formal foil, $\mathrm{CH}_{2} \mathrm{Cl}_{2}$ was used as a solvent, which might be a precursor of the outgassing product hydrochloride $(\mathrm{HCl})$ during irradiation. The number of fragment masses is smaller for polyvinyl acetate and for polyvinyl alcohol, since they are less complex compared to polyvinyl formal with its additional acetale ring subunit.

Fig. 10 compares the outgassing fragments of polyvinyl formal of cryogenic and room temperature irradiation. At cryogenic temperature the spectrum is characterized by the presence of large $\mathrm{H}_{2}(\mathrm{~m} / \mathrm{z}=2)$ and $\mathrm{CO}(\mathrm{m} / \mathrm{z}=28)$ peaks, where

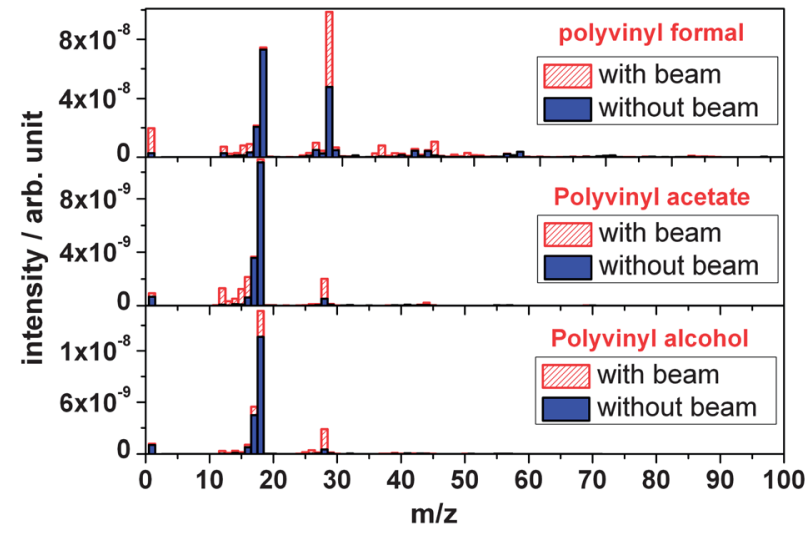

Fig. 9 Outgassing spectra of polyvinyl formal, polyvinyl acetate and polyvinyl alcohol polymers at RT recorded online during irradiation with $4.5 \mathrm{MeV} \mathrm{u}^{-1} \mathrm{Au}$ ions.

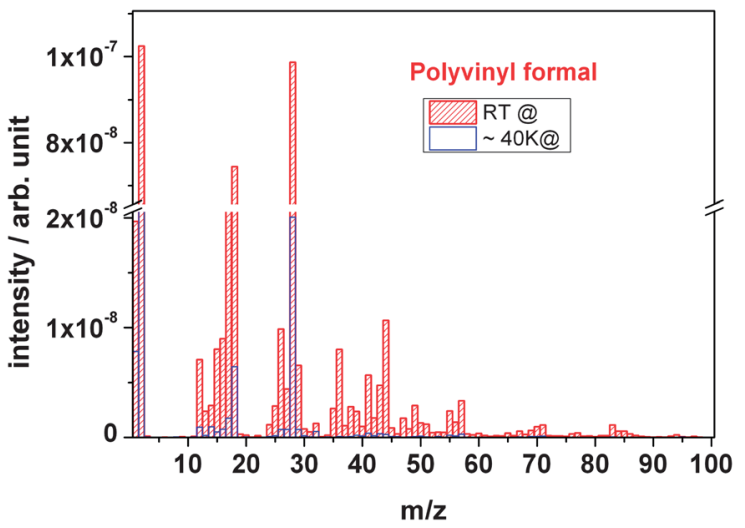

Fig. 10 Outgassing spectra of a polyvinyl formal foil at RT and $40 \mathrm{~K}$ recorded online during irradiation with $4.5 \mathrm{MeV} \mathrm{u}^{-1} \mathrm{Au}$ ions.

$\mathrm{H}_{2}$ is the major gas species formed compared to smaller peaks of $\mathrm{C}, \mathrm{O}, \mathrm{H}_{2} \mathrm{O}$, and $\mathrm{C}_{n} \mathrm{H}_{x}$. The masses with possible fragments are presented in Table 1 together with their relative intensities and probable compound assignments. Under cryogenic conditions, most of the mass signals are significantly smaller compared with those of room temperature irradiation. While the boiling point of hydrogen $\left(\mathrm{H}_{2}\right)$ is very low and thus the gas is not immobilized at $40 \mathrm{~K}$, other molecules are kept in a frozen state particularly the large ones such as acetic acid and larger ketones and aldehydes. Water from the polymer would also be frozen; however, this signal does also arise from the vacuum chamber and is therefore still significantly to be recorded.

In the cryogenic case, it is the combined effect of the direct gas radiolysis and the gas transport out of the matrix which determines which volatiles will most likely be present in the vacuum chamber and will be detected by the mass spectrometer.

The table shows that polyvinyl formal is broken up into a large number of fragments upon ion irradiation. The main product in all cases is hydrogen which is the main component of the polymer with respect to atomic percentage. The acetale subunit bears $10 \mathrm{H}$ atoms ( $+6 \mathrm{C}$ atoms and $2 \mathrm{O}$ atoms), in acetate the atomic ratio $\mathrm{H}: \mathrm{C}: \mathrm{O}$ is $6: 4: 2$ and in alcohol $4: 2: 1$. Since the ion beam cuts all bonds easily, the process will release large quantities of hydrogen. From the hydrocarbon backbone, $\mathrm{C}_{x} \mathrm{H}_{y}$ fragments of different sizes are cut out, mainly the small ones with 1, 2 or $3 \mathrm{C}$-atoms. Since all subunits bear $\mathrm{O}$ atoms, oxygen itself, and its compounds with $\mathrm{H}$ and $\mathrm{C}$ are formed. Therefore, water/hydroxyl on one side, and carbon oxides and aldehydes and ketones on the other side are formed. The amount of smaller fragments, such as formaldehyde and acetaldehyde, is larger than the bigger ones, such as butenal.

The appearance of the large number of fragments can be explained by opening of the acetale dioxane ring with multiple scission, side-group elimination of acetate and alcohol, and backbone scission.

3.2.2 Polyvinyl acetate. Fig. 11 shows the mass spectra of polyvinyl acetate before and during ion irradiation at room temperature. Before the irradiation, characteristic signals appeared at the mass ratio of 17 and 18, corresponding to $\mathrm{OH}$ and 
Table 1 Outgassing fragments of polyvinyl formal during irradiation at room temperature (RT, $297 \mathrm{~K})$ and cryogenic temperature (CT, $40 \mathrm{~K})$; $(\mathrm{r} / \mathrm{i})$ means radical/ion ${ }^{a}$

\begin{tabular}{|c|c|c|c|c|}
\hline 2 & $\mathrm{H}_{2}$ & Hydrogen molecule & 100 & 64 \\
\hline $13-15$ & $\mathrm{CH}_{1-4}$ & Hydrocarbon (r/i): methyl and carbene & $2-8$ & $0.2-0.9$ \\
\hline 16 & $\mathrm{O}$ & Oxygen (r/i) & 9 & 0.7 \\
\hline 17 & $\mathrm{OH}$ & Hydroxyl (r/i) & 2 & 1.7 \\
\hline 28 & $\mathrm{CO} / \mathrm{C}_{2} \mathrm{H}_{4}$ & Carbon monoxide/ethene & 96 & 20 \\
\hline 29 & $\mathrm{CHO}$ & Formaldehyde (r/i) & 6.4 & 0.7 \\
\hline 30 & $\mathrm{CH}_{2} \mathrm{O}$ & Formaldehyde & 0.8 & 0.2 \\
\hline 32 & $\mathrm{CH}_{3} \mathrm{OH}$ & Methanol & 1.2 & 0.5 \\
\hline $37-41$ & $\mathrm{C}_{3} \mathrm{H}_{1-5}$ & Hydro(tri)carbons & $1-5$ & $0-0.3$ \\
\hline 42 & $\mathrm{C}_{2} \mathrm{H}_{2} \mathrm{O}$ & Ketene & 1.7 & 0.2 \\
\hline 59 & $\mathrm{C}_{2} \mathrm{H}_{3} \mathrm{O}_{2}$ & Acetic acid (anion) & 0.2 & $\mathrm{~b}$ \\
\hline 60 & $\mathrm{C}_{2} \mathrm{H}_{4} \mathrm{O}_{2}$ & Acetic acid & 0.3 & $\mathrm{~b}$ \\
\hline 66 & $\mathrm{C}_{5} \mathrm{H}_{6}$ & Cyclopentadiene & 0.1 & $\mathrm{~b}$ \\
\hline 70 & $\mathrm{C}_{4} \mathrm{H}_{6} \mathrm{O}$ & Butenal & 1.0 & $\mathrm{~b}$ \\
\hline $83-84$ & $\mathrm{C}_{4} \mathrm{H}_{3-4} \mathrm{O}_{2}$ & Diketene, dioxin, furanone & $1.1-0.6$ & $\mathrm{~b}$ \\
\hline $85-86$ & $\mathrm{C}_{4} \mathrm{H}_{5-6} \mathrm{O}_{2}$ & Methacrylic acid (r/i), butenoic acid, & $0.6-0.3$ & $\mathrm{~b}$ \\
\hline
\end{tabular}

${ }^{a}$ b: below the limit of detection.

$\mathrm{H}_{2} \mathrm{O}$, respectively. Upon irradiation, the partial pressures of these molecules were increasing and some new types of molecules and ions appeared, including those of hydrogen $\left(\mathrm{H}_{2}, m / z=2\right)$, carbon (C, $m / z=12)$, oxygen $(\mathrm{O}, m / z=16)$, hydroxyl $(\mathrm{OH}, m / z=17)$, water $\left(\mathrm{H}_{2} \mathrm{O}, m / z=18\right)$, hydrocarbons $\left(\mathrm{C}_{n} \mathrm{H}_{x}, m / z=13-15, \mathrm{C}_{2} \mathrm{H}_{2} 26\right)$, carbon monoxide/ethene $\left(\mathrm{CO}, \mathrm{C}_{2} \mathrm{H}_{4} \mathrm{~m} / z=28\right)$, and carbon dioxide/acetaldehyde $\left(\mathrm{CO}_{2}, \mathrm{C}_{2} \mathrm{H}_{4} \mathrm{O}, \mathrm{m} / \mathrm{z}=44\right)$. Above this mass the signals become very small, indicating that heavier fragments are hardly formed (not shown in this spectrum, see Fig. 9). The mass signal $\mathrm{m} / \mathrm{z}=17$ of hydroxyl exhibits only a small intensity in comparison with other outgassing fragments, which indicates that the $\mathrm{OH}$ molecule either comes from the $\mathrm{H}_{2} \mathrm{O}$ molecule or

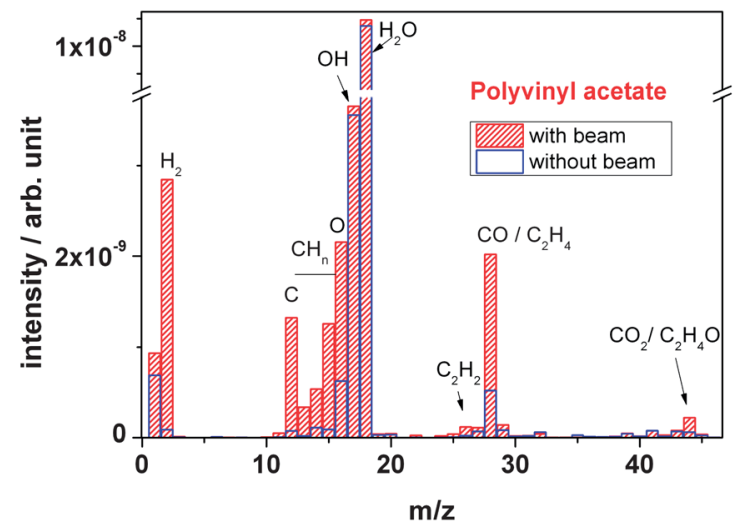

Fig. 11 Outgassing spectra of a polyvinyl acetate foil recorded online during irradiation with $4.5 \mathrm{MeV} \mathrm{u}^{-1} \mathrm{Au}$ ions. from -OH formation from an ester group during irradiation. FTIR spectroscopy of polyvinyl acetate had shown that a new stretching mode of the $-\mathrm{OH}$ band appeared in the region from $3500 \mathrm{~cm}^{-1}$ and $3200 \mathrm{~cm}^{-1}$ with increasing fluence.

In thermal degradation, the main product found by Costa et al. is acetic acid, together with minor amounts of keten, water, methane and the two carbon oxides. ${ }^{26}$ Blasevska-Gilev and Spaseska found $87 \%$ acetic acid, several percent of acetone and benzene, and a few percent of acetaldehyde and cyclopentadiene..$^{30}$ The main products came from side chain elimination, followed by breakdown of the unsaturated polymer backbone. The latter took place in a higher temperature regime.

In contrast to these findings, in ion induced degradation we observe a different mechanism. In thermally induced degradation, the scission of the side chain leads to formation of acetic acid, either by reaction of two acetate side chains, or by a bond break between the ester oxygen bridge and the polymer backbone. ${ }^{26,30}$ Under ion bombardment, almost no fragments with masses corresponding to acetic acid or acetic anhydride have been observed. The only fragments found were those with one $\mathrm{O}$ atom only which is acetaldehyde. This means that in case of ion bombardment, the side chain is preferentially cleaved within the carboxylate group between the oxygen next to the backbone and the keto carbon atom, leading to an aldehyde as fragment.

The remaining oxygen either creates an alcohol group or becomes a keto group by double bond migration and keto-enol tautomerism. The formation of $-\mathrm{OH}$ has been observed with FTIR, as mentioned above, supporting this mechanism. 
The formation of carbon monoxide which appears in large amounts is most likely due to ion induced scission of the formed aldehyde from the side chain and the formed ketone of the backbone. It turns out that ion induced scission leads to smaller fragments, more governed by the high-energy electron excitation process and less by the regular chemical reaction rules.

3.2.3 Polyvinyl alcohol. Fig. 12 shows the mass spectra of polyvinyl alcohol. The outgassing molecules and atoms of polyvinyl alcohol are hydrogen $\left(\mathrm{H}_{2}, \mathrm{~m} / \mathrm{z}=2\right)$, carbon $(\mathrm{C}, \mathrm{m} / \mathrm{z}=$ $12)$, oxygen $(\mathrm{O}, m / z=16)$, hydroxyl $(\mathrm{OH}, m / z=17)$, water $\left(\mathrm{H}_{2} \mathrm{O}\right.$, $m / z=18)$, hydrocarbons $\left(\mathrm{C}_{n} \mathrm{H}_{x}, m / z=13-15,26\right)$ and carbon monoxide/ethene (CO, $\left.\mathrm{C}_{2} \mathrm{H}_{4} m / z=28\right)$, which were found also in PVAc and in PVF. In contrast to PVAc and PVF, hardly any heavier masses are found. This is due to the fact that PVA has non aliphatic side chain or ring structure.

Fig. 13 depicts the mass spectra of PVA and PVAc polymers in comparison. Concerning the observed species, they appear similar. During irradiation, both polymers show an overall increase in peak intensity of the characteristic fragment molecules. However, in PVA the O-based outgassing fragments $\left(\mathrm{H}_{2} \mathrm{O}\right.$, $\mathrm{OH}$ and CO molecules) at mass signals $m / z=18, \mathrm{~m} / z=17$ and $m / z=28$ of PVA exhibit a significantly larger intensity in

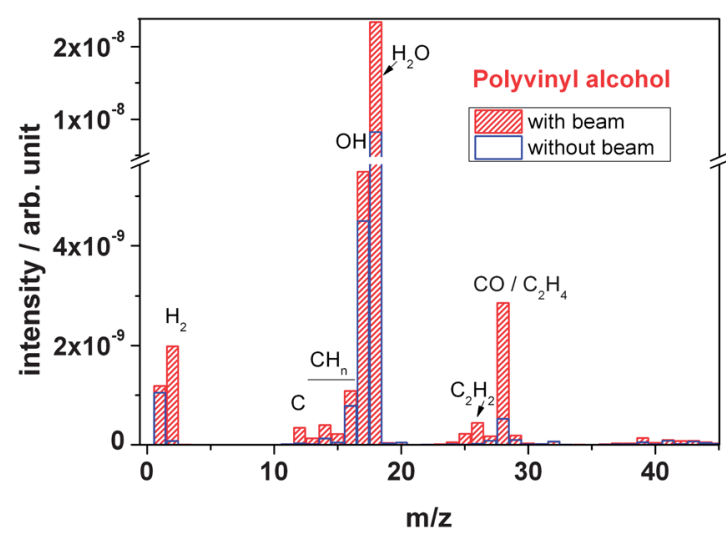

Fig. 12 Outgassing spectra of a polyvinyl alcohol foil at RT recorded online during irradiation with $4.5 \mathrm{MeV} \mathrm{u}^{-1} \mathrm{Au}$ ions.

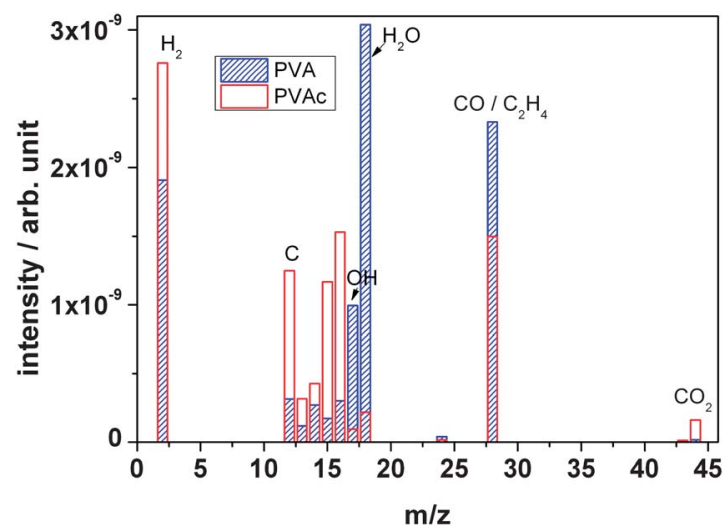

Fig. 13 Outgassing spectra of PVA and PVAc foil recorded online during irradiation with $4.5 \mathrm{MeV} \mathrm{u}^{-1} \mathrm{Au}$ ions. comparison to that of PVAc polymer, which can be explained by the elimination of the $-\mathrm{OH}$ group. The large quantities of $\mathrm{CO}$ are due to scission of the keto-bearing backbone, in accordance with the FTIR observations. In contrast, peak intensities of other outgassing fragments such as hydrogen $\left(\mathrm{H}_{2}\right)$ and hydrocarbon $\left(\mathrm{C}_{x} \mathrm{H}_{y}\right)$ of PVA are smaller than the ones of PVAc.

In thermal degradation studies on PVA, Tsuchiya and Sumi had also found water as the main product, but also aldehydes and ketones, such as acetaldehyde, crotonaldehyde (butenal) and hexadienal, and acetone by means of gas chromatography. ${ }^{27}$ Hay and Holland identified gas phase products by IR and found bands of water and saturated and unsaturated ketones and, in particular, aldehydes at 1715 to $1760 \mathrm{~cm}^{-1} \cdot{ }^{29}$

These findings are similar to the present results. Apparently, elimination of $\mathrm{H}_{2}$ with formation of keto groups and elimination of water with formation of $\mathrm{C}=\mathrm{C}$ double bonds are the main mechanisms both for thermal and ion induced degradation. The difference between the two degradation processes seems to be that in the thermal process reactions to larger fragment units are possible, while in ion induced degradation the fragments remain smaller, in analogy to the observations on PVAc.

3.2.4 Outgassing during heating up. In Fig. 10 it has been shown that ion beam induced degradation of polyvinyl formal at a temperature of $40 \mathrm{~K}$ had yielded considerably less masses and mass intensities of fragment molecules. In principal, there are two possible explanations for this observation: one is that the radiation damage is lower at cryogenic temperature, the other one, as mentioned before, is that the fragment molecules have been trapped in the polymer matrix in a frozen state. The latter explanation is more likely since, according to the FTIR result, the polymer is also degraded at low temperature. In order to check whether or not small fragment molecules have been trapped at low temperature, the sample was slowly heated up to RT in order to set the molecules free. Fig. 14 shows a plot of outgassing profiles of four masses as a function of the temperature. It turns out that the gas release starts immediately when the temperature rises above $40 \mathrm{~K}$. Mass $\mathrm{m} / z=28$ is the major outgassing product. The graph shows that two peaks appear in the low temperature region at $73 \mathrm{~K}$ and $98 \mathrm{~K}$ during

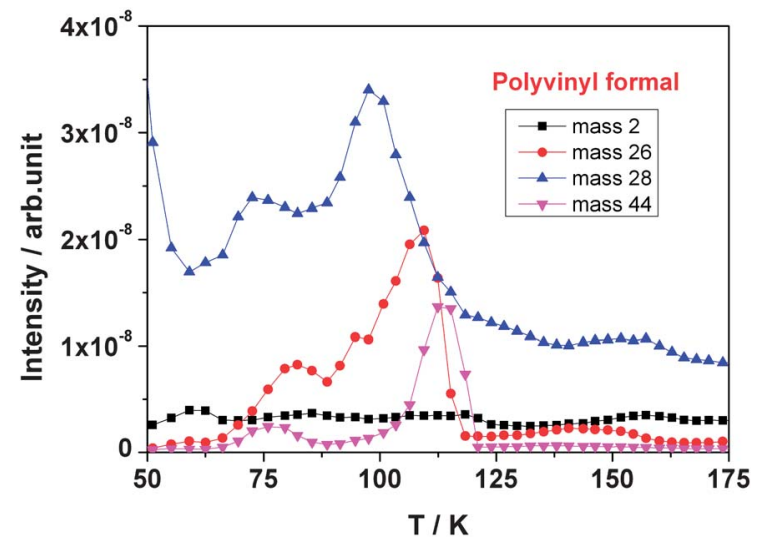

Fig. 14 Outgassing profiles of different masses $\mathrm{m} / \mathrm{z}$ during heating of polyvinyl formal after the exposure to $4.5 \mathrm{MeV} \mathrm{u}^{-1} \mathrm{Au}$ ions. 
heating up. This is an indication that either the species is trapped in two binding states, which is not likely, or that there are two molecules of the same mass. For $m / z=28$, two compounds are reasonable: $\mathrm{CO}$ and $\mathrm{C}_{2} \mathrm{H}_{4}$. Their boiling temperatures at normal pressure give an indication of the sequence of appearance during heat up: while carbon monoxide boils at $81.5 \mathrm{~K}$, the boiling temperature of ethane is $169.5 \mathrm{~K}$. As a consequence, the peak at $73 \mathrm{~K}$ can most likely be assigned to carbon monoxide and the peak at $98 \mathrm{~K}$ to ethane. In the temperature region (65-130) $\mathrm{K}$ peaks appear of $\mathrm{m} / \mathrm{z}=26, \mathrm{~m} / \mathrm{z}=$ 28 and $m / z=44$, corresponding to ethyne $(m / z=26)$, carbon monoxide/ethane $(\mathrm{m} / \mathrm{z}=28)$, and carbon dioxide/acetaldehyde $(\mathrm{m} / \mathrm{z}=44)$. In the latter case, the compound evaporating at higher temperature shows a larger peak area, indicating that the aldehyde is the main product, in accordance with the mechanism postulated on the basis of FTIR and MS measurements. The boiling of $\mathrm{H}_{2}$ is not visible at $40 \mathrm{~K}$ because it is below the presented temperature area. This is consistent with the results shown in Fig. 10.

\section{Discussion}

When analyzing the non-oxidative chemical degradation reactions taking place by high-energy heavy ion irradiation of polymers in vacuum, one has to take into account that regular reaction steps of organic chemistry and their rules can only partially be applied since around the track of the heavy ions in the polymer the energy level is extremely high. In this nonequilibrium regime, thermodynamics of chemical reactions at regular reaction temperatures do not apply. When the ion crosses the polymer, it releases huge amounts of its kinetic energy into the material by exciting electrons and by setting them free from their covalent bonds. These electrons themselves ionize atoms and create further energetic electrons in collision cascades. These electrons are easily able to cut bonds. Table 2 shows the bond dissociation energies of the atoms involved in increasing order. ${ }^{31}$ The dissociation energies of the covalent bonds of the involved atoms in the polyvinyl polymers are between 300 and $500 \mathrm{~kJ} \mathrm{~mol}^{-1}$, corresponding to about 3 to $5 \mathrm{eV}$ of the individual interatomic bonds.

The energy transferred from the energetic ion into the polymer can be derived from theory. The software SRIM (Stopping and Range of Ions in Solids) calculates ion-atominteractions including electronic and atom bond structure which is long-range affected in terms of electron excitations and plasmons. ${ }^{32}$ By using the bond strengths of Table 2, SRIM gave for each single Au ion for a PVF foil of a thickness of $20 \mu \mathrm{m}$ more

Table 2 Bond dissociation energies, from ref. 31

\begin{tabular}{lll}
\hline Bond & $\mathrm{kJ} \mathrm{mol}^{-1}$ & eV per bond \\
\hline $\mathrm{C}-\mathrm{C}$ & 346 & 3.59 \\
$\mathrm{C}-\mathrm{O}$ & 358 & 3.71 \\
$\mathrm{H}-\mathrm{C}$ & 411 & 4.25 \\
$\mathrm{H}-\mathrm{O}$ & 459 & 4.75 \\
$\mathrm{C}=\mathrm{C}$ & 602 & 6.23
\end{tabular}

than 2000 displaced atoms, i.e. atoms cut out of their positions within the polymeric chain, and an average transferred energy of around $1600 \mathrm{eV}$ per $100 \mathrm{pm}$ length of the ion track in the polymer, see Table 3 . The $\mathrm{C}-\mathrm{C}$ bond length is $154 \mathrm{pm} .{ }^{33}$ This means that all types of bonds suffer from scissions; even single atoms can be cut out of the polymer backbone. Often, the bond scission is homolytic, leading to radicals. Radicals and ions created under these non-equilibrium conditions are metastable and highly reactive such as $\mathrm{O}, \mathrm{OH}$ and $\mathrm{C}$. When they meet a chemical reaction partner and when they are able to get rid of their excess energy, they will react. Those species set free from the bonds in the near-surface region can leave the polymer. In the present case of high vacuum, the mean free path $\lambda$ of the species is considerably larger than the vacuum chamber dimensions and the distance $x$ between polymer sample and the mass spectrometer, $\lambda>1 \mathrm{~m}>x .^{34}$ Whatever species leaves the sample into the direction of the spectrometer does not meet any other molecule for reaction. Others are reflected from the chamber walls until they most probably disappear in the vacuum pump or, by chance, hit the mass spectrometer orifice. This is the reason why highly reactive and unstable species are to be found in the mass spectrum. Another reason, of course, is the electron impact ionization process in the mass spectrometer which does also create such species. When fragments are formed in depth of the polymer, they have to diffuse to the surface. On their way, they may react and form new bonds. The smaller the molecules are, the easier they can escape. This is the reason why large numbers of hydrogen molecules and also water and carbon monoxide are found.

Hence, one part of the degradation reaction products are nonequilibrium species, one part of the products obeys the rules of organic chemical reactions. When the ion has passed and its created energetic electrons have cooled down to room temperature, regular organic chemistry applies and the reaction products can be compared to those found in thermal degradation.

It has been found for mass spectrometry of PVA that the ion induced process yielded less heavy fragments than the thermally induced one. In the thermodynamically controlled equilibrium process, the chance for chemical reactions to larger molecules is higher than in the non-equilibrium process by energetic ions in vacuum where small molecular fragments have a better chance to be ejected from the solid before reaction.

Table 3 Transferred energy $\mathrm{d} E / \mathrm{d} x$ (per $100 \mathrm{pm}$ ion track length $x$ ) and integral radiation damage per ion (accumulated number of $\mathrm{C}, \mathrm{O}$, and $\mathrm{H}$ atoms, displaced from their position in the polymer chain, up to the given depth), for $4.5 \mathrm{MeV} \mathrm{u}^{-1} \mathrm{Au}$ ions in PVF, calculated by SRIM (ref. 32) for different depths/thickness of the material. The average ion range is $66.3 \pm 0.4 \mu \mathrm{m}$, i.e. in a depth of e.g. $100 \mu \mathrm{m}$ there is no more damage $(\mathrm{d} E / \mathrm{d} x=0)$

\begin{tabular}{llc}
\hline Position (depth) & $\mathrm{d} E / \mathrm{d} x$ & Displacement per ion \\
\hline $10 \mu \mathrm{m}$ & $1667 \mathrm{eV}$ & 979 \\
$20 \mu \mathrm{m}$ & $1712 \mathrm{eV}$ & 2158 \\
$60 \mu \mathrm{m}$ & $297 \mathrm{eV}$ & 18857 \\
$100 \mu \mathrm{m}$ & $0 \mathrm{eV}$ & 39264
\end{tabular}


Based on the results and on these considerations, in the following a few reaction paths are proposed which may explain the main findings. Apart from them, however, several other degradation reactions occur, especially ion induced backbone scission which can take place at any position due to the very high energy input with a locally highly non-equilibrium character. Also, a large number of free radical reactions will happen, since the ion beam process produces lots of them. Also, more complex reactions such as inter-molecular cyclisation reactions which lead to aromatic compounds or to the heterocyclic structures, where both FTIR and MS give evidence, are not shown since they are of minor importance, in contrast to thermal degradation.

Fig. 15a shows the proposed main ion induced degradation reaction in polyvinyl alcohol. In FTIR it had been observed that the $-\mathrm{OH}$ and $-\mathrm{CH}$ bands had decreased under ion irradiation, at the same time a slight growth of a $-\mathrm{C}=\mathrm{O}$ keto band was observed. The main fragments were $\mathrm{H}_{2}$ and $\mathrm{H}_{2} \mathrm{O}$. The latter is created by scission of the alcohol function and a neighbouring hydrogen, leading to both the observed reduction of the above mentioned bands and an increase in the $\mathrm{C}=\mathrm{C}$ bands. Another reaction path is elimination of hydrogen, leaving back oxygen at the polymer backbone as a $-\mathrm{C}=\mathrm{O}$ keto group. An indirect reaction path is double bond migration to the next carbon atom, with a neighbouring - $\mathrm{OH}$ group, leading to an enol. As described in Erlenmeyers rule ${ }^{35}$ the keto form is, in general, more stable than its enol tautomer. This is also the reason why polyvinyl alcohol is not made via polymerisation of its monomer vinyl alcohol, which is unstable and exists mainly as its tautomer acetaldehyde, but indirectly by polymerization of vinyl acetate and hydrolysis of the ester bonds. As a consequence, a ketone-type $-\mathrm{C}=\mathrm{O}$ bond is formed resulting from keto-enol tautomerism. Hence, the reaction leads to two products: a keto group and/or a $\mathrm{C}=\mathrm{C}$ double bond, potentially a polyene.

In Fig. 15b, the degradation of the acetate subunit is depicted. The mechanism is mainly based on the elimination of the acetate side chain, thus forming either a $\mathrm{C}=\mathrm{O}$ keto group with hydrogen elimination at the backbone $\mathrm{C}$ atom or to an $-\mathrm{OH}$ group when hydrogen is abstracted from a neighbouring carbon atom, thus forming a $\mathrm{C}=\mathrm{C}$ double bond. If double bond migration takes place, again a keto-enol tautomerisation might happen.

As a consequence of the reactions, the acetate bands decrease in intensity, and, to a certain extent, also the aliphatic bands. This has been observed by FTIR. This mechanism is also consistent with the mass spectrometric observation of acetic aldehyde and its dehydrogenated radical or ion $\mathrm{CH}_{3} \mathrm{CO}$ as specific molecular fragment product, next to hydrocarbons and carbon oxides. In contrast to this reaction, thermal degradation favours the formation of acetic acid as main reaction product.

These reactions also take place in polyvinyl formal. Both the reduction in ester carbonyl vibration, and formation of keto groups, and an increase in unsaturated $\mathrm{C}=\mathrm{C}$ bonds with a decrease of the aliphatic $-\mathrm{C}-\mathrm{H}$ ones are observed, together with the above mentioned fragments. In contrast to PVA and PVAc, however, the mass 28, corresponding to $\mathrm{CO}$, is the largest part of the fragments after hydrogen. Its intensity is double as high as (a)

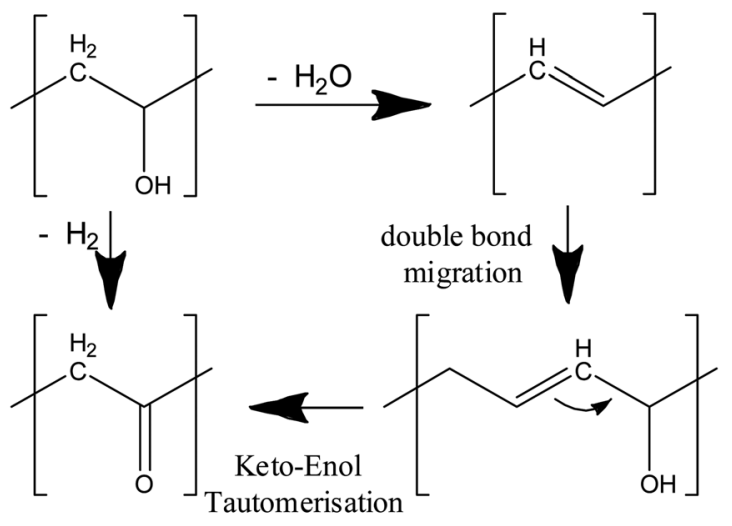

(b)

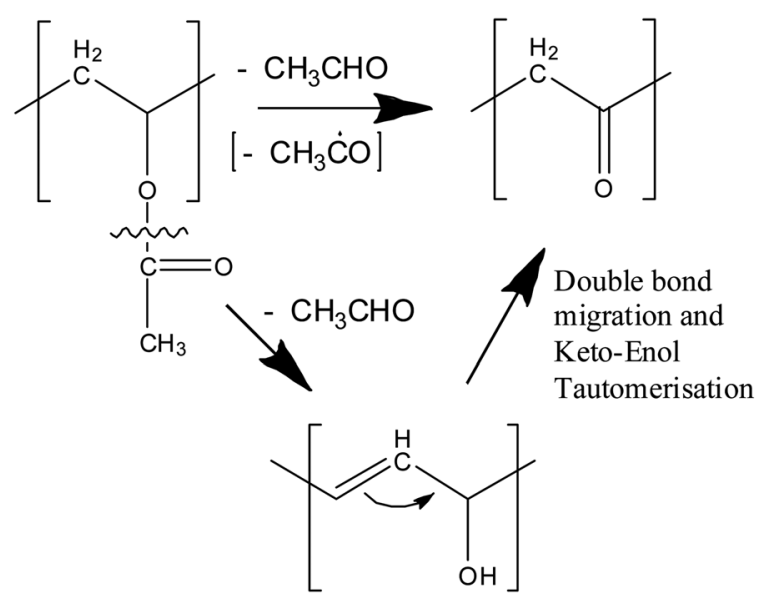

(c)
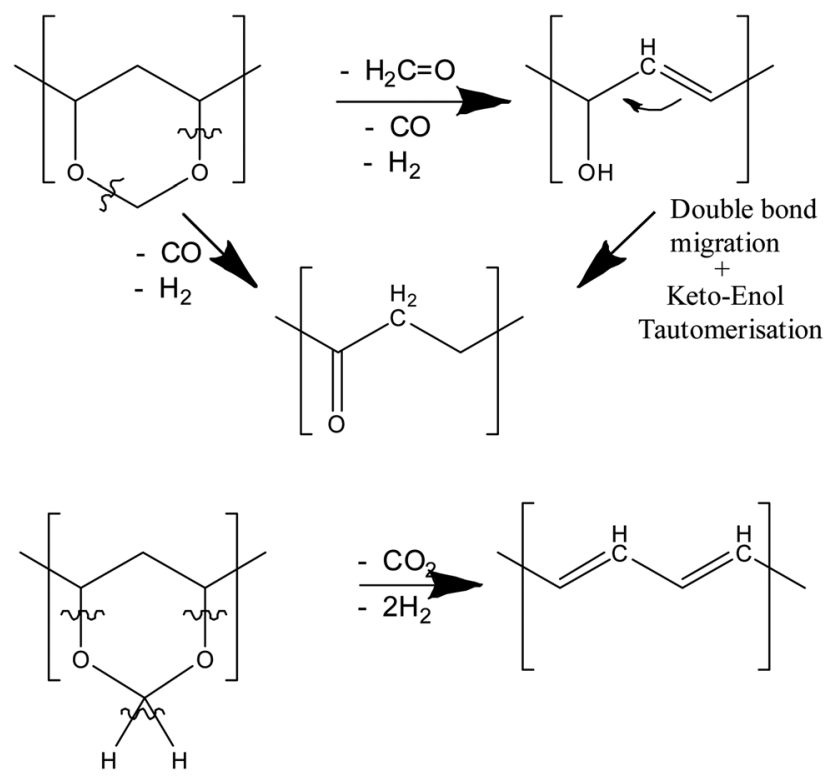

Fig. 15 Proposed ion induced main degradation reactions of polyvinyl polymers, (a) polyvinyl alcohol, (b) polyvinyl acetate, (c) polyvinyl acetale. 
that of PVAc and PVA. Also, $\mathrm{H}_{2} \mathrm{O}$ and $\mathrm{CO}_{2}$ are formed in large quantities. From this observation, we conclude that in addition to the side chain eliminations of PVA and PVAc, it is the scission of the acetale subunit which creates both the additional fragments. Fig. 15c shows the formation of $\mathrm{CO}$ and ethene combined with formation of $-\mathrm{OH}$ or $-\mathrm{C}=\mathrm{O}$ keto groups, the formation of formaldehyde, as well as the creation of polyenes with adjacent $\mathrm{C}=\mathrm{C}$ bonds with emission of $\mathrm{CO}_{2}$ and $\mathrm{H}_{2}$. These reactions are in accordance with both the results of FTIR and mass spectroscopy.

The role of $-\mathrm{OH}$ is complex. On one hand its elimination has been shown with PVA, on the other hand, there are production reactions from acetate and acetale subunits in PVF. PVF polymer shows no significant net changes of the band intensity, because PVAc and PVA show reverse tendency of $-\mathrm{OH}$ band development with increasing ion fluence. This explains the unexpected seeming stability of the $-\mathrm{OH}$ groups of PVF.

The FTIR spectrum of polyvinyl formal at $40 \mathrm{~K}$ shows very similar results in comparison to the room temperature experiments. In contrast, in the outgassing experiments under cryogenic irradiation conditions, most of the mass signals are significantly smaller compared to room temperature irradiation. This result indicates that at low irradiation temperatures small fragments are frozen in and accumulated in the sample, which is correlated to the results of heating experiments. This observation is not only relevant for the degradation mechanism, but is also of technical importance. Whenever a component which has been working under cryogenic conditions, either in space or in a superconducting coil of an accelerator, is heated up, by irradiation from sun in space or due to maintenance in an accelerator, it will release large amounts of gases, leading to gas pressure increase. This may cause damage, particularly, when the material is already weakened by ion induced degradation. It should also be emphasized that a low temperature does well protect a polymer from degradation, trivially by prohibiting temperature-induced reactions, but it does not help when highly energetic ions are involved leading to nonequilibrium conditions with an extreme local electronic energy input.

\section{Summary}

This work reports the modification of polyvinyl polymers by energetic heavy ions. To gain information about the influence of different side chains three different polymers (PVF, PVAc and PVA) were analysed with online mass spectrometric analysis and in situ FTIR spectroscopy. The degradation processes occurring in polyvinyl polymers under heavy ion irradiation have been analyzed and the results were correlated. The measurements of the chemical reaction products by mass spectrometry as well as structural characterizations by FTIR give evidence for severe ion induced modification of the polymers, independent of the macroscopic temperature. The polymers are degraded in all parts of side-chains and backbones, with a large number of volatile degradation products. In the ion induced process, the polymers essentially are dehydrogenated, since the loss of hydrogen is larger than the loss of carbon, and also oxygen is lost. As a consequence, double bonds are formed; the polymer is "carbonized".

The considerable structural changes will lead to a modification/deterioration of specific macroscopic properties, such as electrical resistance and mechanical strength, and are therefore of importance for applications in environments with energetic particles, such as space and accelerators.

\section{Acknowledgements}

This work was supported by the Bundesministerium für Bildung und Forschung (BMBF), Germany, under Project no. 05P09RDRB0 (PT-DESY). The authors wish to thank Prof. C. Trautmann and Drs D. Severin and M. Bender of GSI for support with the irradiation experiments, and the operating team for providing excellent stable beam conditions.

\section{Notes and references}

1 Polymer Handbook, ed. J. Brandrup, E. H. Immergut and E. A. Grulke, John Wiley \& Sons, Hoboken, NJ, 2005.

2 Polymer Data Handbook, ed. J. E. Mark, Oxford University Press, Oxford, 2009.

3 I. Augustin, Nucl. Instrum. Methods Phys. Res., Sect. B, 2007, 261, 1014.

4 P. Spiller and G. Franchetti, Nucl. Instrum. Methods Phys. Res., Sect. A, 2006, 561, 305.

5 L. Koch, J. J. Engelmann, P. Goret, E. Juliusson, N. Petrou, Y. Rio, A. Soutoul, B. Byrnak, N. Lund and B. Peters, Astron. Astrophys., 1981, 102, 11.

6 A. Chapiro, Nucl. Instrum. Methods Phys. Res., Sect. B, 1995, 105,5 .

7 J. Davenas, I. Stevenson, N. Celette, S. Cambon, J. L. Gardette, A. Rivaton and L. Vignoud, Nucl. Instrum. Methods Phys. Res., Sect. B, 2002, 191, 653.

8 E. Balanzat, N. Betz and S. Bouffard, Nucl. Instrum. Methods Phys. Res., Sect. B, 1995, 105, 46.

9 T. Steckenreiter, E. Balanzat, H. Fuess and C. Trautmann, Nucl. Instrum. Methods Phys. Res., Sect. B, 1997, 131, 159.

10 D. Severin, W. Ensinger, R. Neumann, C. Trautmann, G. Walter, I. Alig and S. Dudkin, Nucl. Instrum. Methods Phys. Res., Sect. B, 2005, 236, 456.

11 D. Severin, E. Balanzat, W. Ensinger and C. Trautmann, J. Appl. Phys., 2010, 108, 024901.

12 T. Seidl, A. Plotnikov, E. Mustafin, R. Lopez, D. Severin, E. Floch, C. Trautmann, A. Golubev, A. Smolyakov, D. Tommasini and W. Ensinger, Polym. Degrad. Stab., 2012, 97, 2396.

13 T. Seidl, O. Baake, U. H. Hossain, M. Bender, D. Severin, C. Trautmann and W. Ensinger, Nucl. Instrum. Methods Phys. Res., Sect. B, 2012, 272, 400.

14 O. Baake, T. Seidl, U. H. Hossain, A. O. Delgado, M. Bender, D. Severin and W. Ensinger, Rev. Sci. Instrum., 2011, 82, 045103. 15 J. K. Haken and R. L. Werner, Spectrochim. Acta, 1971, 27, 343. 16 J. K. Wilmshurst, J. Mol. Spectrosc., 1957, 1, 201.

17 A. R. Katrizky, J. M. Lagowski and J. A. T. Beard, Spectrochim. Acta, 1960, 16, 954. 
18 J. J. Lucier and F. F. Bentley, Spectrochim. Acta, 1964, 20, 1. 19 J. K. Haken and R. L. Werner, Br. Polym. J., 1971, 3, 157. 20 J. K. Haken and R. L. Werner, Br. Polym. J., 1973, 5, 451.

21 M. Hesse, H. Meier and B. Zeeh, Spectroscopic Methods in Organic Chemistry, Thieme, Zürich, 2007.

22 N. Grassie, Trans. Faraday Soc., 1952, 48, 379.

23 B. B. Troitskii, G. A. Razuvaev, L. V. Khokolova and G. N. Bortnikov, J. Polym. Sci., Polym. Symp., 1973, 42, 1363. 24 A. Ballistieri, S. Foti, G. Montaudo and E. Scamporrino, J. Polym. Sci., Polym. Chem. Ed., 1980, 18, 1147.

25 B. J. Holland and J. N. Hay, Polymer, 2002, 43, 2207.

26 L. Costa, M. Avataneo, P. Bracco and V. Brunella, Polym. Degrad. Stab., 2002, 77, 503-510.

27 Y. Tsuchiya and K. Sumi, J. Polym. Sci., Part A-1: Polym. Chem., 1969, 7, 3151.
28 P. S. Thomas, J.-P. Guerbois, G. F. Russell and B. J. Briscoe, J. Therm. Anal. Calorim., 2001, 64, 501.

29 B. J. Holland and J. N. Hay, Polymer, 2001, 42, 6775.

30 J. Blasevska-Gilev and D. Spaseska, J. Univ. Chem. Technol. Metall., 2005, 40, 287.

31 J. E. Huheey, E. A. Keiter and R. L. Keiter, Inorganic Chemistry, HarperCollins, New York, 1993.

32 J. F. Ziegler, J. P. Biersack and M. D. Ziegler, The Stopping and Range of Ions in Solids, software package SRIM 2013, Lulu Press, Morrisville, 2006.

33 D. R. Lide, Tetrahedron, 1962, 17, 125.

34 A. Chambers, Modern Vacuum Physics, CRC Press, Boca Raton, 2005.

35 H. D. Jakubke and H. Jeschkeit, Concise Encyclopedia Chemistry, Walter de Gruyter, Berlin, 1994. 